\title{
The effects of airmass history on new particle formation in the free troposphere: case studies
}

\author{
D. R. Benson ${ }^{1}$, Li-Hao Young ${ }^{1}$, Shan-Hu Lee ${ }^{1}$, T. L. Campos ${ }^{2}$, D. C. Rogers ${ }^{2}$, and J. Jensen ${ }^{2}$ \\ ${ }^{1}$ Kent State University, Department of Chemistry, Kent, OH, USA \\ ${ }^{2}$ National Center for Atmospheric Research, Earth Observing Laboratory, Broomfield, CO, USA
}

Received: 4 September 2007 - Published in Atmos. Chem. Phys. Discuss.: 8 October 2007

Revised: 12 March 2008 - Accepted: 20 May 2008 - Published: 18 June 2008

\begin{abstract}
Recent aircraft studies showed that new particle formation (NPF) is very active in the free troposphere. And, these observations lead to a new question: when does NPF not occur? Here, we provide case studies to show how different meteorological parameters affect NPF in the upper troposphere, using the aerosol size distributions measured at latitudes from $18^{\circ} \mathrm{N}-52^{\circ} \mathrm{N}$ and altitudes up to $14 \mathrm{~km}$ during the NSF/NCAR GV Progressive Science Missions. About 95\% of the total samples showed the NPF feature with median number concentrations of particles with diameters from 4 to $9 \mathrm{~nm}\left(N_{4-9}\right), 288 \pm 199 \mathrm{~cm}^{-3}$, and the total particle number concentrations with diameters from 4 to $2000 \mathrm{~nm}\left(N_{4-2000}\right)$, $500 \pm 259 \mathrm{~cm}^{-3}$. Surface areas were in general very low in the free troposphere, $1.58 \pm 0.87 \mu \mathrm{m}^{2} \mathrm{~cm}^{-3}$, which in part explains the high frequency of NPF measured in this region, but there was no distinctive difference in surface area for the NPF and non-NPF cases. Our case studies show that rather airmass history is more important for nucleation in this region. Weak- or non-events did not display uplifting of airmasses. On the other hand, strong NPF events were usually associated with uplifting of airmasses, although there were also NPF cases in which uplift did not occur, consistent with the previous observations (Young et al., 2007). NPF tends to easily occur in the free troposphere because of low surface areas and low temperatures (Carslaw and Kärcher, 2006), but because of the low aerosol precursors in this region, vertical motion (that can bring higher concentrations of aerosol precursors from low altitude source regions to higher altitudes) can play a critical role. Latitude dependence of new particles also shows higher particle concentrations in the midlatitude and subtropics tropopause region than in the tropics, consistent with Hermann et al. (2003).
\end{abstract}

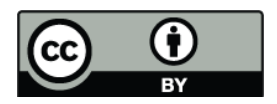

Correspondence to: Shan-Hu Lee (slee19@kent.edu)

\section{Introduction}

Recent aircraft studies showed new particle formation (NPF) in the free troposphere and lower stratosphere (de Reus et al., 1998, 1999; Nyeki et al., 1999; Twohy et al., 2002; Lee et al., 2003; Young et al., 2007) with high frequencies (up to 86-100\%) (Young et al., 2007) and strong magnitudes (up to $45000 \mathrm{~cm}^{-3}$ ) (Twohy et al., 2002). Hermann et al. (2003) have provided so far the most comprehensive statistical analysis of NPF in the Northern Hemisphere tropopause region from three-year aircraft measurements; elevated particle number concentrations of $1500-8000 \mathrm{~cm}^{-3}$ were frequently observed in a wide range of latitudes $\left(5^{\circ} \mathrm{N}-\right.$ $50^{\circ} \mathrm{N}$ ). Twohy et al. (2002) showed especially high number concentrations of new particles up to $45000 \mathrm{~cm}^{-3}$ in the midlatitudes, associated with deep convection. Minikin et al. (2003)'s aircraft studies showed relatively high concentrations of Aitken mode particles (up to $1000 \mathrm{~cm}^{-3}$ ) even in the Southern Hemisphere, where the anthropogenic emission of $\mathrm{SO}_{2}$ is much lower than in the Northern Hemisphere; their comparison of particle number concentrations in the Northern and Southern Hemisphere indicates that new particles are directly related to aerosol precursor sources. NPF events take place near or in orographic clouds (Wiedensohler el al., 1997; Mertes et al., 2005) and stratus clouds (Hegg et al., 1992) during the nighttime, and even in cirrus clouds (Lee et al., 2004). As NPF was observed in a wide range of the free troposphere and lower stratosphere (Ström et al., 1999; Twohy et al., 2002; Hermann et al., 2003; Minikin et al., 2003; Lee et al., 2003, 2004; Young et al., 2007), it is also important to understand when NPF does not occur or when weak NPF occurs.

We present results from NPF studies during the National Science Foundation (NSF) and National Center for Atmospheric Research (NCAR) NSF/NCAR GV Progressive Science Missions. The GV is also known as HIAPER, the High-performance Instrumented Airborne Platform for

Published by Copernicus Publications on behalf of the European Geosciences Union. 
Table 1. The median values of the measured particle concentration from 4-9 nm $\left(N_{4-9}\right)$, the particle concentration from 4-2000 nm $\left(N_{4-2000}\right)$, and other key meteorological parameters during the entire NSF/NCAR GV Progressive Science Missions. All 7 research flights are included here. The median absolute deviation values are also included. NPF indicates NPF. In total, 5181 data points of $30 \mathrm{~s}$ average data are included here.

\begin{tabular}{lccc}
\hline & All Days & NPF & Non-NPF \\
\hline$N_{4-9}\left(\mathrm{~cm}^{-3}\right)$ & $275 \pm 198$ & $288 \pm 199$ & $4.93 \pm 4.88$ \\
$N_{4-2000}\left(\mathrm{~cm}^{-3}\right)$ & $457 \pm 273$ & $500 \pm 259$ & $60.8 \pm 42.3$ \\
Surface Area $\left(\mu \mathrm{m}^{2} \mathrm{~cm}^{-3}\right)$ & $1.58 \pm 0.87$ & $1.52 \pm 0.84$ & $2.32 \pm 1.49$ \\
Temperature $(\mathrm{K})$ & $228 \pm 11$ & $227 \pm 8$ & $244 \pm 29$ \\
Relative Humidity Over Ice $(\%)$ & $13.3 \pm 11.0$ & $11.4 \pm 8.8$ & $24.9 \pm 24.0$ \\
Potential Temperature (K) & $325 \pm 14$ & $327 \pm 12$ & $310 \pm 26$ \\
$\mathrm{H}_{2} \mathrm{O}$ Mixing Ratio (ppmv) & $115 \pm 75$ & $102 \pm 58$ & $423 \pm 398$ \\
Altitude $(\mathrm{km})$ & $9.52 \pm 2.31$ & $9.87 \pm 1.94$ & $5.67 \pm 4.72$ \\
Fraction of samples $(\%)$ & 100 & 95 & 5 \\
\hline
\end{tabular}

Environmental Research. The Progressive Science Mission was the first science mission onboard the GV and there were seven days of research flights (Young et al., 2007). There is the Part I paper by Young et al. (2007) that used two days of measurements in the midlatitude tropopause region (on 1 and 7 December 2005) from this mission to show how stratosphere and troposphere air mixing enhances NPF. The present study is the Part II paper, and we want to investigate when no-/weak- NPF takes place. There is also a third manuscript (Lee et al., 2008) that discusses nighttime ultrafine particles observed from GV.

\section{NSF/NCAR GV Progressive Science Missions}

The NSF/NCAR GV Progressive Science Mission NPF studies took place from 21 November to 19 December 2005 in Broomfield, Colorado. The flights covered the western half of the United States, and parts of Canada and Mexico in latitude from $18^{\circ} \mathrm{N}$ to $62^{\circ} \mathrm{N}$ and in longitude from $92^{\circ} \mathrm{W}$ to $130^{\circ} \mathrm{W}$. There were three days of nighttime NPF experiments (2,12 and 19 December 2005) in order to investigate the effects of sun exposure (Lee et al., 2008). Nighttime studies in this region are rare.

Aerosol sizes and concentrations were measured with the University of Denver nuclei mode aerosol size spectrometer (NMASS) and focused cavity aerosol spectrometer (FCAS). These instruments are described in detail elsewhere (Jonsson et al., 1995; Brock et al., 2000; Lee et al., 2003, 2004; Young et al., 2007) and have been used for NPF studies in the upper troposphere and lower stratosphere previously (Lee et al., 2003, 2004; Young et al., 2007). Briefly, NMASS has five condensation nucleus counters that measure cumulative number concentrations of aerosols larger than $4,8,15,30$ and $60 \mathrm{~nm}$, respectively. FCAS is a light scattering instrument and sizes aerosols from 90 to $2000 \mathrm{~nm}$. Using an inversion
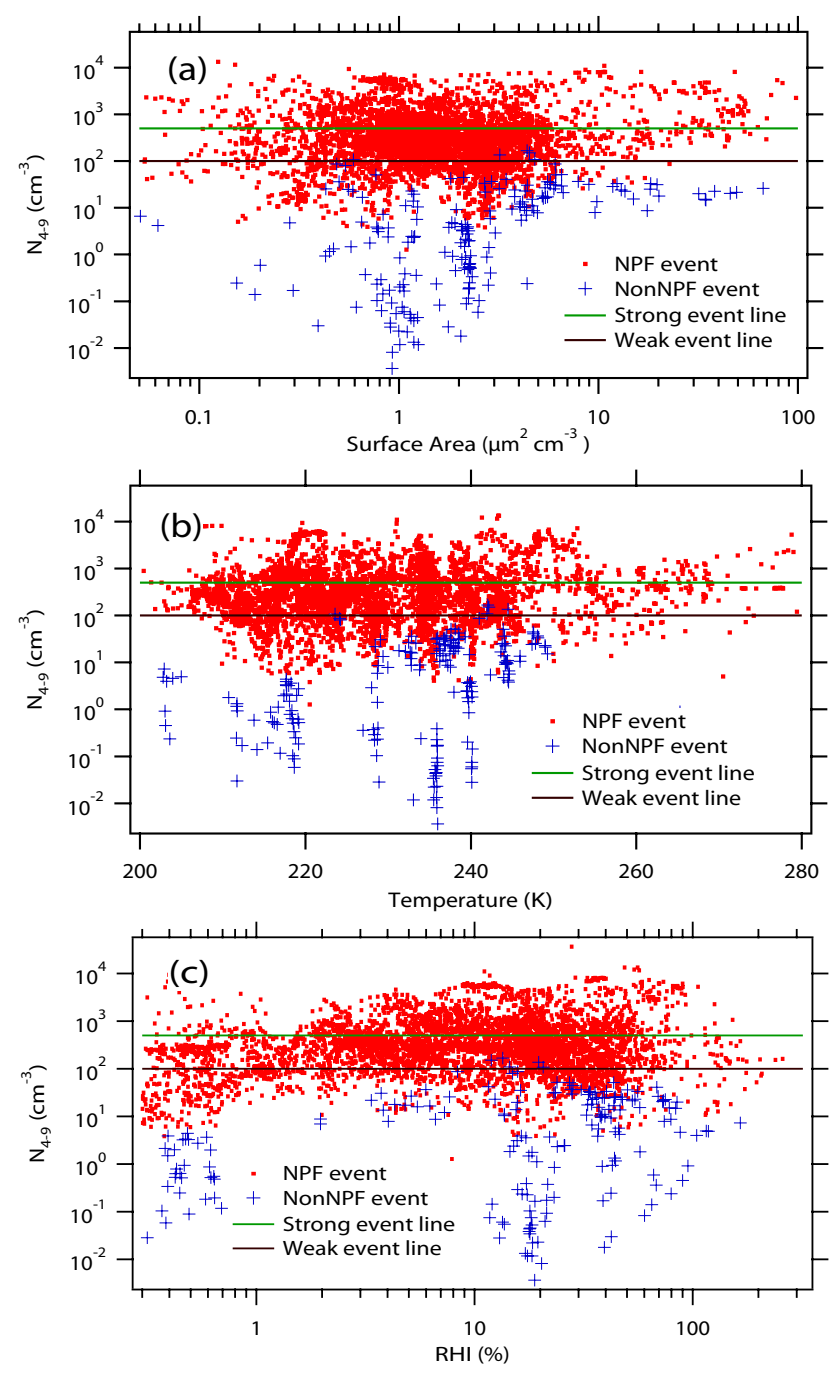

Fig. 1. The measured $N_{4-9}$ as a function of surface area, temperature and RHI during the entire NSF/NCAR GV Progressive Science Mission. All 7 research flights are included here. The data are split into two categories, NPF (red circles) and non-NPF (blue crosses), as discussed in the text. The horizontal bars indicate the level of the strong- $\left(N_{4-9}>500 \mathrm{~cm}^{-3}\right)$ (green) and weak-NPF $\left(N_{4-9}<75 \mathrm{~cm}^{-3}\right)$ (brown); note that the weak event line also is nearly the same as that the upper limit of the non-NPF $N_{4-9}$, indicating that both non- and weak-events have sufficiently low $N_{4-9}$.

algorithm, size distributions from 4 to $2000 \mathrm{~nm}$ are obtained. The inversion also includes sampling efficiency, anisokinetic inlet effects, and diffusion loss etc.

The criteria for NPF are (i) $N_{4-9}>1 \mathrm{~cm}^{-3}$, (ii) more than $1 / 15$ of $N_{4-2000}$ are $N_{4-9}$, and (iii) particles from 4 to $6 \mathrm{~nm}$ $\left(N_{4-6}\right)$ are higher than those from 6 to $9 \mathrm{~nm}\left(N_{6-9}\right)$ (Young et al., 2007). A non-NPF event is defined when at least one of these three criteria is not satisfied. Non-events tended to have size distributions without a peak in the size range $<10 \mathrm{~nm}$, a 
clear indication of more aged aerosols than for NPF cases (Fig. 3c). Each NPF event is further classified as a strong or week event by comparing with "background" concentrations, which are referred to as the median concentration values from all events shown in Table 1. Strong events are for the cases when $N_{4-9}>500 \mathrm{~cm}^{-3}$ (which is approximately the same value as that one median absolute deviation value higher than the median $N_{4-9}$ for all events, $(275+198) \mathrm{cm}^{-3}$ in this case; similarly to Young et al. (2007)); weak events are defined when $N_{4-9}<100 \mathrm{~cm}^{-3}$ (one median absolute deviation value lower than the median $N_{4-9}$ for all events, which is (275-198) $\mathrm{cm}^{-3}$, and we took $100 \mathrm{~cm}^{-3}$ here for simplicity). As shown in Fig. 1, weak- and non-NPF cases show a similar upper level of $N_{4-9}$, indicating that even though these two cases may have different size distributions (e.g., $N_{4-6}$ vs. $N_{6-9}$ ), they both have low $N_{4-9}$. Previous NPF studies in the free troposphere made by other investigators have used the criterion that the measured total $\mathrm{CN}$ concentrations are higher than the background $\mathrm{CN}$ concentrations to identify NPF cases (Twohy et al., 2003 and numerous references cited therein), for example. In comparison, our criteria for NPF are more quantitative, yet consistent with these cited studies. For example, our non-NPF samples had much lower $N_{4-9}$ and $N_{4-2000}$ than the median concentrations from all days of experiments (Table 1) (that is, background concentrations) so they will also be non-NPF cases even with the NPF criterion used in these cited studies.

There were only less than $2 \%$ of the measurement data from this mission showed RH values greater than $100 \%$. All case studies presented here were taken from cloud free sections of the flight (e.g., $\mathrm{RH}<60 \%$ ) so new particles were not affected by clouds. Our previous studies also have shown that shattering of clouds in the inlet of the NMASS and FCAS instruments has little effects on the measured aerosol number concentrations (while there are some effects on mass concentrations) (Lee et al., 2004), so the measured new particles were unlikely affected by cloud processing.

\section{Results}

\subsection{Overall}

Table 1 summarizes the measured particle concentrations and meteorological conditions during this mission, including the measured $N_{4-9}, N_{4-2000}$, surface area density of preexisting aerosols, temperature, relative humidity over ice (RHI), the potential temperature, water mixing ratio, and altitude, along with the fraction of samples that satisfy (thus NPF), or do not satisfy (non-NPF), the NPF criteria. Overall, there were $95 \%$ of NPF and $5 \%$ of nonNPF cases during the entire Progressive Science Missions (Table 1). Furthermore, 30\% of NPF cases were strongNPF and 25\% were weak-NPF. For NPF events, the median $N_{4-9}$ value was $288 \pm 199 \mathrm{~cm}^{-3}$ and the median $N_{4-2000}$ was
$500 \pm 259 \mathrm{~cm}^{-3}$. On the other hand, non-NPF events had a median $N_{4-9}$ of $4.93 \pm 4.88 \mathrm{~cm}^{-3}$ and a median $N_{4-2000}$ of $60.8 \pm 42.3 \mathrm{~cm}^{-3}$, both much lower than the overall $N_{4-9}$ of $275 \pm 198 \mathrm{~cm}^{-3}$ and $N_{4-2000}$ of $457 \pm 273 \mathrm{~cm}^{-3}$. The important feature here is that a small fraction of measurements (5\%), the non-NPF cases, showed an obvious and large deviation from the $N_{4-9}$ median. Surface area concentrations were very low in this region, $1.58 \pm 0.87 \mu \mathrm{m}^{2} \mathrm{~cm}^{-3}$. For NPF events surface areas were $1.52 \pm 0.84 \mu \mathrm{m}^{2} \mathrm{~cm}^{-3}$, and for non-events $2.32 \pm 1.49 \mu \mathrm{m}^{2} \mathrm{~cm}^{-3}$; however, the ranges of surface area were in fact the same for NPF and nonNPF events (Fig. 1). Our low surface areas are consistent with other studies $\left(4-6 \mu \mathrm{m}^{2} \mathrm{~cm}^{-3}\right.$ on average (Young et al., 2007), $3.4 \pm 1.7 \mu \mathrm{m}^{2} \mathrm{~cm}^{-3}$ (Lee et al., 2003) and less than $10 \mu \mathrm{m}^{2} \mathrm{~cm}^{-3}$ (Twohy et al., 2003; Carslaw and Kärcher, 2006)) and these low surface areas in general also explain the high frequency of NPF observed in this region. The higher median surface area for non-NPF is probably related to the fact that most of the non-NPF events were measured in the lower altitudes (Fig. 1b and c and Table 1). For example, for the non-event samples, the median temperature was $\sim 244 \mathrm{~K}$, higher than that for NPF cases $(\sim 228 \mathrm{~K})$ (Table 1$)$.

Our case studies discussed below will show weak- or nonNPF events did not show uplifting of the airmass, whereas strong NPF cases were closely associated with uplifting. In the present study, uplifting of the airmass is defined based on the NOAA HYSPLIT backward trajectory outputs (e.g., airmass altitude dependence with time) (Draxler and Rolph, 2003). Uplifting is referred to as the cases when the airmass was uplifted from a lower altitude, usually less than $2 \mathrm{~km}$ above ground level, to higher altitudes at an uplift rate greater than $3 \mathrm{~km}$ per day and the airmass was exposed to these low altitude source regions for at least 2 days before the vertical motion. On the other hand, if this rate was less than $3 \mathrm{~km}$ per day or if the airmass spent less than two days at an altitude of $2 \mathrm{~km}$ or less, we considered such a case as a non-uplifting event. It is noted that this "uplifting" process is slightly different from the conventional "convection", which is usually defined as a small scale process on the order of kilometers or less in size (the model output from NOAA HYSPLIT calculations only has a grid resolution of 1 degree and cannot truly resolve convective systems).

HYSPLIT trajectories were run for a large number of cases other than those presented in two case studies in Sects. 3.2 and 3.3. However, because of the tremendous amount of data points we did not calculate for each individual data point. Also, when calculating HYSPLIT trajectories, one can only input the UTC time in hours for the starting time and our measurements were in $1 \mathrm{~s}$ and the data presented here were averaged in $30 \mathrm{~s}$. Regardless, for NPF events (Table 1), in general it seemed that the majority of the time $(>50 \%)$ the events displayed some degree of uplift. On the other hand, all non-NPF events found in the free troposphere region did not experience uplifting of airmasses (Sect. 3.2). 

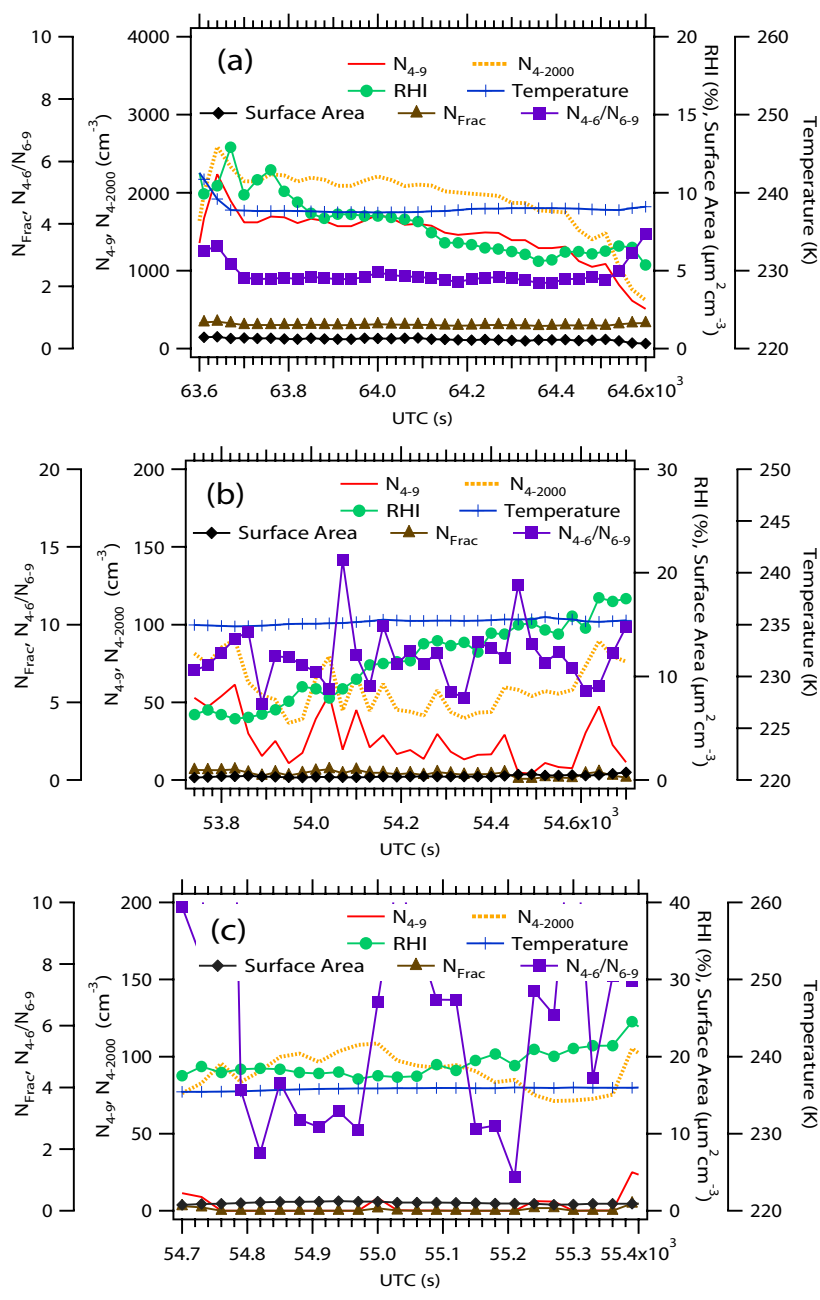

Fig. 2. The measured total particle number concentration $\left(N_{4-2000}\right)$, ultrafine particle concentration $\left(N_{4-9}\right)$, fraction of $N_{4-9}$ in $\mathrm{N}_{4-2000}\left(N_{\text {Frac }}\right)$, ratio of the particle number concentration in the size range from 4 to $6 \mathrm{~nm}\left(N_{4-6}\right)$ over that from 6 to $9 \mathrm{~nm}$ $\left(N_{6-9}\right)$, surface area, temperature and relative humidity over ice (RHI) as a function of universal time for several different events that were observed on 19 December 2005. (a) A strong NPF event observed during the day which occurred at $57^{\circ} \mathrm{N}, 116^{\circ} \mathrm{W}, 7.6 \mathrm{~km}$ and temperatures around $238 \mathrm{~K}$. (b) A weak NPF event observed during the day which occurred at $50^{\circ} \mathrm{N}, 112^{\circ} \mathrm{W}, 8.0 \mathrm{~km}$ and temperatures around $235 \mathrm{~K}$. (c) A non NPF event observed during the day which occurred at $52^{\circ} \mathrm{N}, 113^{\circ} \mathrm{W}, 8.0 \mathrm{~km}$ and temperatures around $237 \mathrm{~K}$. See Fig. 2 for measured aerosol size distributions and Fig. 3 for backward trajectory calculations.

\subsection{Case Study I (19 December 2005): Strong-, Weak-, and} Non-NPF Events

To understand how different meteorological parameters affect NPF, a variety of types of NPF events must be analyzed including strong-, weak- and non-events. However, because there were only 186 data points $(5 \%)$ that showed
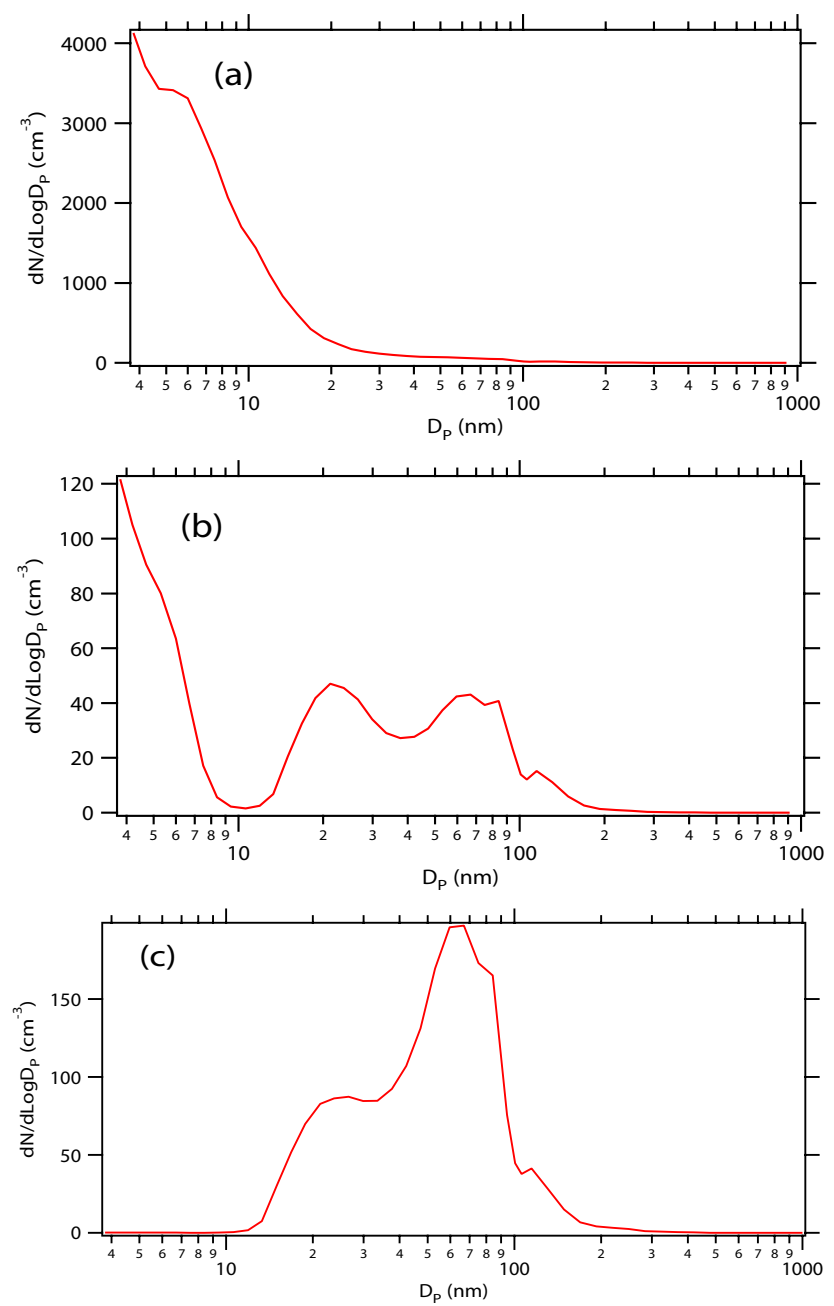

Fig. 3. The measured, average particle size distributions for the events shown in Fig. 2. The letters here correspond to those from Fig. 2 and each distribution is for the time period shown for the corresponding event from Fig. 2. The dip at $\sim 100 \mathrm{~nm}$ in the size distribution comes from the inversion program when combining the NMASS and the FCAS data together and may not be representative of the actual aerosols sizes. The same is true for Fig. 6. The size mode at $20 \mathrm{~nm}$ or $70 \mathrm{~nm}$ (b and c) is representative of more aged particles that grew from newly formed fresh particles.

absolute non-NPF events (Table 2) and some of these data points were also rather sporadically distributed, we provide here only one case study including a non-NPF event. Figure 2 shows strong- (a) weak- (b), and non-NPF (c) event cases, for the measured $N_{4-2000}, N_{4-9}$, fraction of $N_{4-9}$ in $N_{4-2000}\left(N_{\text {Frac }}\right)$, ratio of the particle number concentration in the size range from 4 to $6 \mathrm{~nm}\left(N_{4-6}\right)$ over that from 6 to $9 \mathrm{~nm}\left(N_{6-9}\right)\left(N_{4-6} / N_{6-9}\right)$, surface area, temperature and RHI as a function of universal time for 19 December 2005's flight. On this day, the GV flew north to latitude $62^{\circ} \mathrm{N}$ before sunrise and returned to Colorado after sunrise, returning 
Table 2. The meteorological parameters derived from the five day NOAA HYSPLIT trajectory calculations for the case studies used in the present study. Median, maximum, and minimum values of the altitude, temperature, RHI, cumulative precipitation and cumulative solar flux intensity are shown.

\begin{tabular}{|c|c|c|c|c|c|c|c|c|c|c|c|}
\hline \multicolumn{12}{|c|}{ Case Study 1: 19 December 2005} \\
\hline \multirow[t]{2}{*}{ Event } & \multicolumn{3}{|c|}{ Altitude $(\mathrm{km})$} & \multicolumn{3}{|c|}{ Temperature (K) } & \multicolumn{3}{|c|}{ RHI (\%) } & \multirow{2}{*}{$\begin{array}{c}\text { Prec. }(\mathrm{mm}) \\
\text { Cumul. }\end{array}$} & \multirow{2}{*}{$\frac{\text { Solar Flux }\left(\mathrm{kW} \mathrm{m}^{-2}\right)}{\text { Cumul. }}$} \\
\hline & Med. & Min & $\operatorname{Max}$ & Med. & Min & $\operatorname{Max}$ & Med. & Min & Max & & \\
\hline Non & 7.5 & 6.9 & 9.0 & 242 & 220 & 248 & 57 & 29 & 90 & 1.8 & 17.2 \\
\hline Weak & 6.4 & 2.2 & 9.2 & 251 & 219 & 284 & 74 & 12 & 99 & 10.2 & 19.3 \\
\hline Strong & 2.2 & 0.8 & 9.0 & 276 & 216 & 288 & 72 & 27 & 92 & 12.4 & 22.6 \\
\hline \multicolumn{12}{|c|}{ Case Study II: 12 December 2005} \\
\hline Weak & 8.3 & 6.2 & 9.9 & 244 & 223 & 265 & 40 & 2 & 95 & 8 & 58.5 \\
\hline Strong & 0.6 & 0.1 & 10.4 & 292 & 224 & 298 & 85 & 0 & 98 & 44 & 54.5 \\
\hline
\end{tabular}

along a similar track. This flight was made in the upper troposphere region (altitudes 8 to $14 \mathrm{~km}$ ) for most of the time and had a $\sim 4 \mathrm{~h}$ of daytime and another $\sim 4 \mathrm{~h}$ of nighttime measurements. The case studies shown here are taken from the daytime measurement. The strong event occurred at $57^{\circ} \mathrm{N}, 116^{\circ} \mathrm{W}$, and $7.6 \mathrm{~km}$, the weak event occurred at $50^{\circ} \mathrm{N}$, $112^{\circ} \mathrm{W}$, and $7.6 \mathrm{~km}$, and the non-event was found in a similar geographical region, $52^{\circ} \mathrm{N}, 113^{\circ} \mathrm{W}$, and $8.0 \mathrm{~km}$ (and thus all three events took place at similar temperatures $<240 \mathrm{~K}$ ). Figure 3 shows the average aerosol size distributions taken for the periods corresponding to these three events (Fig. 2).

There are substantial differences in the number concentration and size distribution between all three of these events. The strong event had $N_{4-9}$ of $1500 \mathrm{~cm}^{-3}$ and $N_{4-2000}$ of $2000 \mathrm{~cm}^{-3}$, the weak event had $N_{4-9}$ of $20 \mathrm{~cm}^{-3}$ and $N_{4-2000}$ of $60 \mathrm{~cm}^{-3}$, and the non event had $N_{4-9}$ of $5 \mathrm{~cm}^{-3}$ and $N_{4-2000}$ of $100 \mathrm{~cm}^{-3}$ (failing to satisfy one of the NPF criteria, the ratio of $N_{4-9}$ over $\left.N_{4-2000}\left(N_{\text {Frac }}\right)>6 \%\right)$. The strong event shows clearly fresh new particles in the size range $<10 \mathrm{~nm}$ as does the weak event, but the strong event has a much higher particle concentrations for the smaller particles and the weak event has peaks at $20 \mathrm{~nm}$ and $70 \mathrm{~nm}$. The non-event shows almost no particles in the $<10 \mathrm{~nm}$ range and shows more aged aerosols with the highest aerosol mode at around $70 \mathrm{~nm}$. RHI was actually highest $(20 \%)$ for the nonevent compared to the weak event $(15 \%)$ and strong event (8\%) case. The surface area was comparable $\left(\sim 1 \mu \mathrm{m}^{2} \mathrm{~cm}^{-3}\right)$ for all three events. The surface areas measured at event times are often related to altitudes, with higher surface areas at lower altitudes (Young et al., 2007).

Differences among the three events can also be seen in the back trajectory data from HYSPLIT. The strong event had a higher amount of cumulative precipitation $(12.4 \mathrm{~mm}) \mathrm{com}-$ pared to the weak event $(10.2 \mathrm{~mm})$ and non event $(1.8 \mathrm{~mm})$ as is shown in Table 2. The solar flux was also slightly higher for the strong event $\left(22.6 \mathrm{~kW} \mathrm{~m}^{-2}\right)$ than the weak- $\left(19.3 \mathrm{~kW} \mathrm{~m}^{-2}\right)$ and non-event $\left(17.2 \mathrm{~kW} \mathrm{~m}^{-2}\right)$. However, the distinctive difference between the three events is the airmass history from the previous five days (Fig. 4). These trajectories show two main differences. The first difference is the altitude that the airmasses come from. For the strong NPF event, the airmass originated from a much lower altitude $(1 \mathrm{~km})$ three days prior to the event, whereas the airmass for the weak event originated from about $2 \mathrm{~km}$ and the airmass for the non event was in the upper troposphere $(7 \mathrm{~km})$ for the past 5 proceeding days. Furthermore, for the strong event, the airmass was uplifted over $6 \mathrm{~km}$ in the span of a day, whereas the airmass for the weak event rose $6 \mathrm{~km}$ in three days. Such differences suggest that the airmass from the strong NPF event underwent a significant extent of vertical motion and rapidly brought higher concentrations of the expected aerosol precursors (e.g., $\mathrm{H}_{2} \mathrm{SO}_{4}, \mathrm{NH}_{3}$, organic compounds and water vapor, as well as $\mathrm{OH}$ and sulfur compounds that can be oxidized to form $\mathrm{H}_{2} \mathrm{SO}_{4}$, including $\mathrm{SO}_{2}$ ) from lower altitudes to aid in NPF at higher altitudes with lower temperatures. It is also possible that air mixing might occur when the humid and warm air was rapidly uplifted to higher altitudes and mixed with the cold and dry air at the higher altitudes and this case, a steep gradient of temperature and RH took place to enhance nucleation rates because nucleation is a non-linier process as discussed in Nilsson and Kulmala (1998). For the non-event, there was no uplifting present at all. It is noted that it was consistent that other non-event cases all did not have vertical motion, clearly underlying the importance of large scale vertical motion for nucleation in this high altitude region.

3.3 Case Study II (12 December 2005): Strong- and WeakEvents

Figures 5 and 6 show graphs for a strong and weak NPF event occurring on 12 December 2005. On 12 December 2005, the GV flew from Colorado $\left(40^{\circ} \mathrm{N}\right.$ latitude) south to latitude 

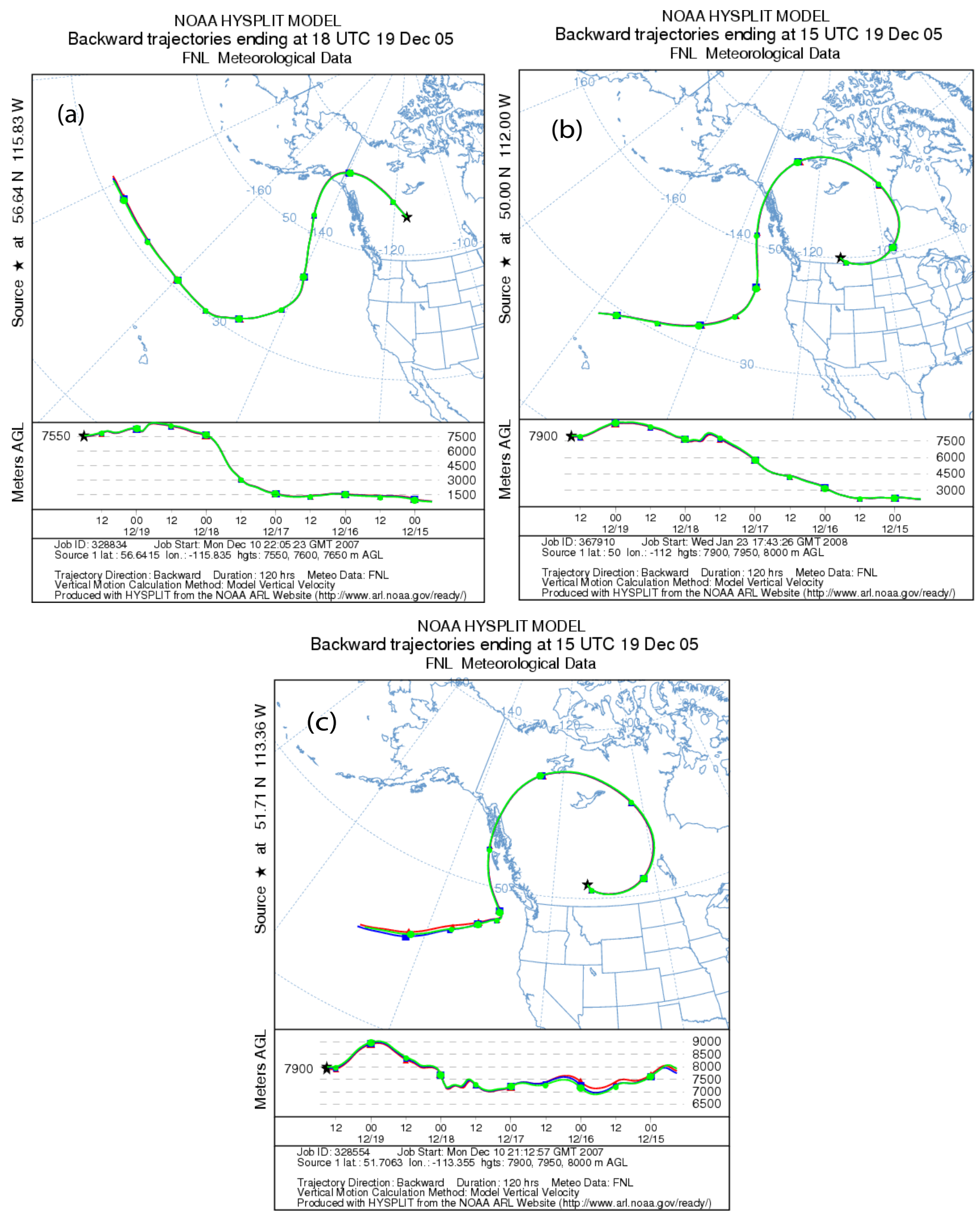

Fig. 4. NOAA HYSPLIT back trajectories for the airmasses for the strong- (upper left panels) (corresponding to Figs. 2a and 3a), weak(upper right panels) (Figs. 2b and 3b), and non-event (bottom left panels) (Figs. 2c and 3c) on 19 December 2005. The star indicates where the event occurred. Altitude variations as a function of the number of days prior to the event are also shown $(12 \mathrm{~h}$ of interval). 

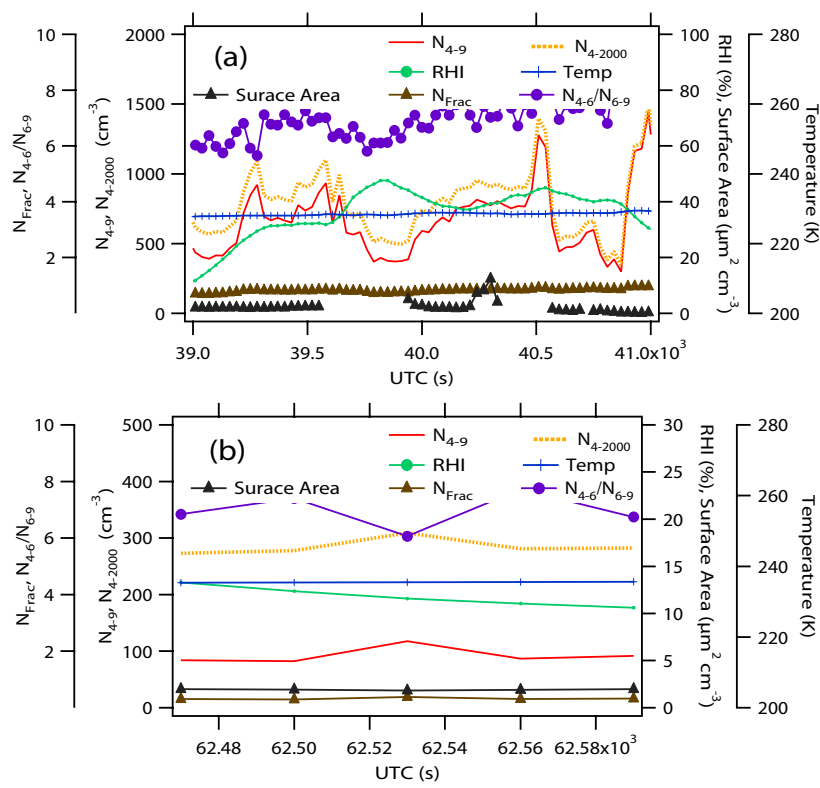

Fig. 5. The same as Fig. 2 except for a strong (a) and weak (b) NPF event occurring on 12 December 2005. The strong event occurred before sunrise (nighttime) at $36^{\circ} \mathrm{N}, 115^{\circ} \mathrm{W}$, and $10 \mathrm{~km}$. The weak event occurred during the day at $37^{\circ} \mathrm{N}, 111^{\circ} \mathrm{W}$, and $9 \mathrm{~km}$.

$18^{\circ} \mathrm{N}$ before sunrise and returned along the same track to Colorado after sunrise by flying through similar longitudes, latitudes, and altitudes. The strong event occurred before sunrise (nighttime) at $36^{\circ} \mathrm{N}, 115^{\circ} \mathrm{W}$, and $10 \mathrm{~km}$ while the weak event occurred after sunrise during the day at $37^{\circ} \mathrm{N}$, $111^{\circ} \mathrm{W}$, and $9 \mathrm{~km}$. Both events occurred at temperatures below $240 \mathrm{~K}$.

Similarly to the previous case study, there were substantial differences in number concentration and size distribution between the strong- and the weak-events. The strong event had $N_{4-9}$ of $700 \mathrm{~cm}^{-3}$ and $N_{4-2000}$ of $800 \mathrm{~cm}^{-3}$, whereas the weak event had $N_{4-9}$ of $90 \mathrm{~cm}^{-3}$ and $N_{4-2000}$ of $280 \mathrm{~cm}^{-3}$. The strong event also shows many more particles in the size range $<10 \mathrm{~nm}$, whereas the weak event shows similar amounts of smaller and larger particles. RHI was higher $(40 \%)$ for the strong event compared to the weak event $(12 \%)$. The surface area was also comparable $\left(\sim 2 \mu \mathrm{m}^{2} \mathrm{~cm}^{-3}\right)$ for both events.

Once again the HYSPLIT trajectory shows differences between the two events. The strong event had a higher amount of cumulative precipitation ( $44 \mathrm{~mm}$ ) compared to the weak event $(8 \mathrm{~mm})$ as is shown in Table 2. The solar flux, however, was comparable for both cases $\left(\sim 55 \mathrm{~kW} \mathrm{~m}^{-2}\right)$. The distinctive difference between the strong and weak events is the back trajectory from the previous five days (Fig. 7). These trajectories show the same differences as the previous case study. For the strong NPF event, the airmass originated from a much lower altitude (ground level) three days prior to
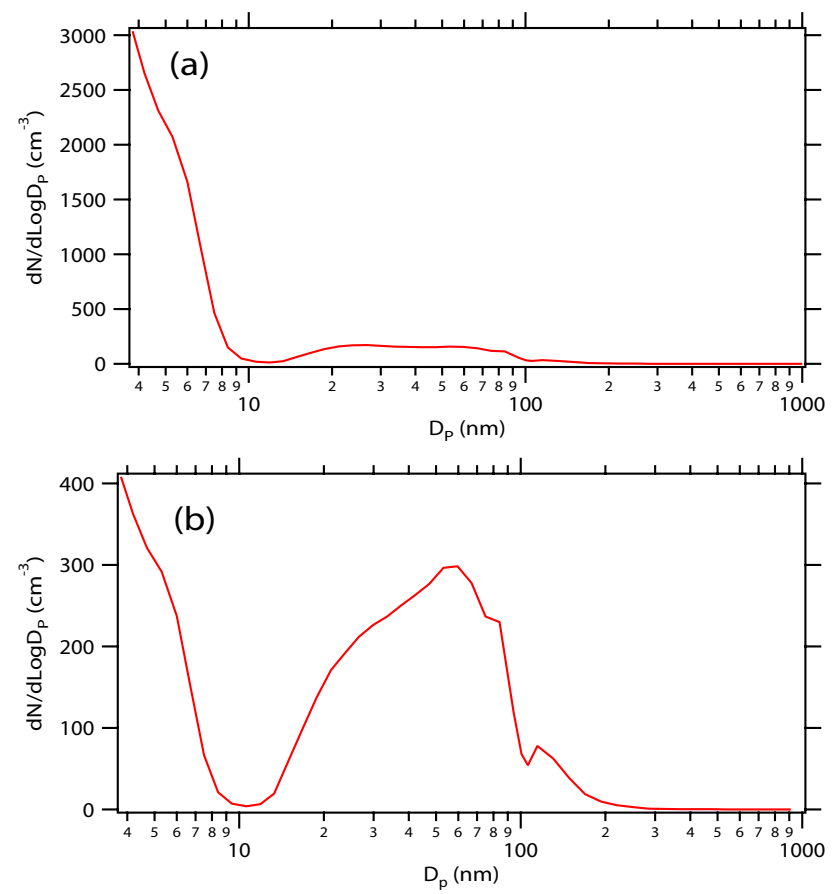

Fig. 6. The measured, average particle size distribution for the events from Fig. 5. The letters here correspond to those from Fig. 5 and each distribution is for the time period shown for the corresponding event from Fig. 5.

the event, whereas the airmass for the weak event was only exposed to altitudes as low as $7 \mathrm{~km}$ a day prior to the event and was actually at higher altitudes $(\sim 9 \mathrm{~km}) 2$ to 3 days prior to the event. The strong event experienced rapid vertical motion ( $10 \mathrm{~km}$ in 2 days), whereas the weak event experienced far less an extent of vertical motion (only $2 \mathrm{~km}$ in a day). As in the previous case study, this could be a reason why the strong event had such high levels of new particle concentration compared to the weak event.

\subsection{Latitude dependence of new particles}

Figure 8 shows the latitude dependence of ultrafine particles for all 7 science flights measured at for three different temperature and altitude regions: temperature $>250 \mathrm{~K}$ (altitude $<6 \mathrm{~km}), 230 \mathrm{~K}<$ temperature $<250 \mathrm{~K}(6 \mathrm{~km}<$ altitude $<9 \mathrm{~km})$, and $200 \mathrm{~K}<$ temperature $<230 \mathrm{~K} \quad(9 \mathrm{~km}<$ altitude $<14 \mathrm{~km})$. These results show that at altitudes from 9 to $14 \mathrm{~km}$, particle concentrations are higher in the subtropics and midlatitudes than in the tropics, consistent with the Hermann et al. (2003) trend; both the present study and Hermann et al. (2003) were mostly conducted near the tropopause region in the midlatitudes at similar latitude ranges. It has been shown that air mixing induced by convection and the stratosphere and troposphere exchange is strong in the midlatitude (Pan et al., 2007) and these air mixing processes 

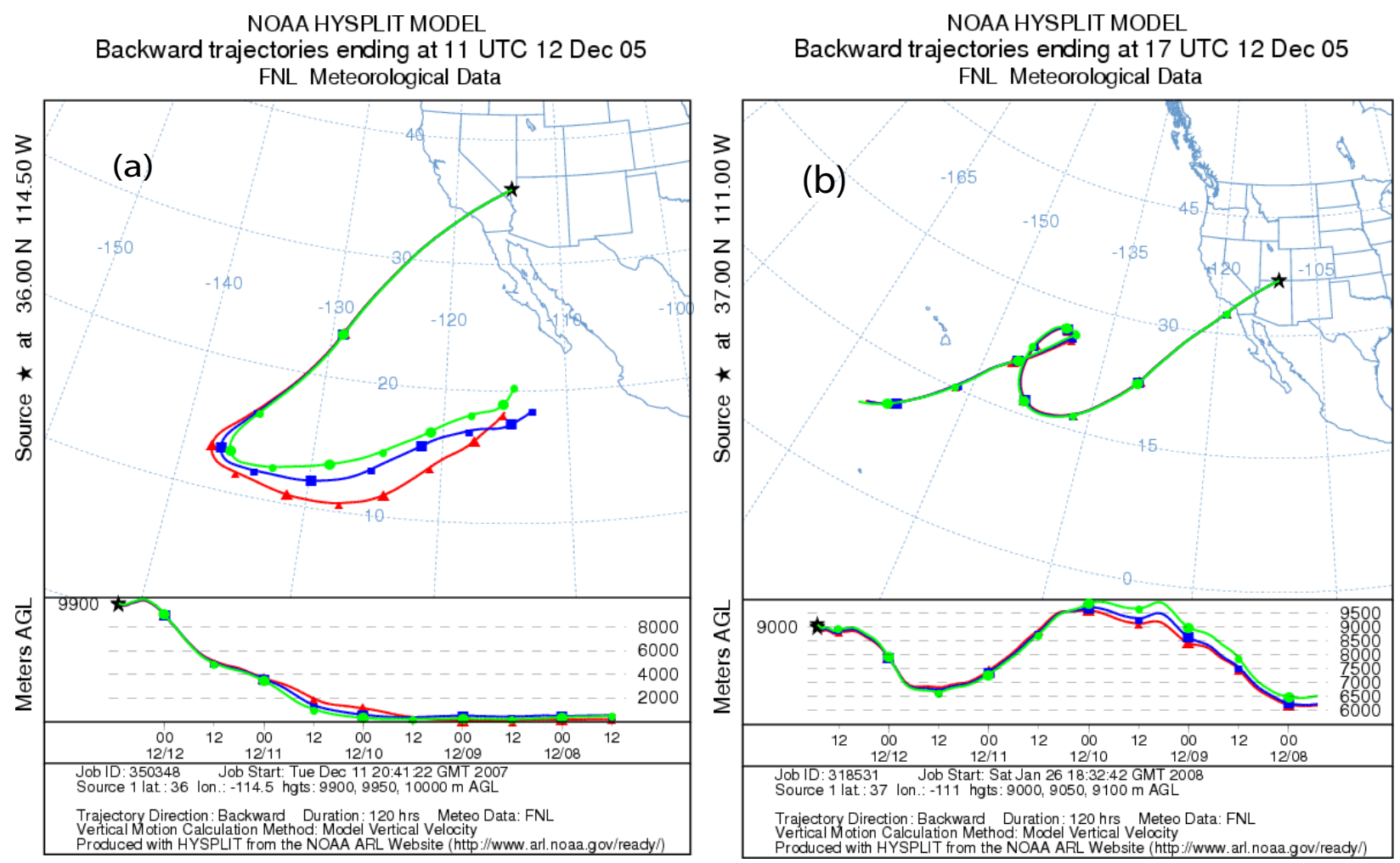

Fig. 7. The same as Fig. 4, except for the strong (left) (corresponding to Figs. 5a and 6a) and weak (right) (Figs. 5b and 6b) NPF events occurring on 12 December 2005.

can enhance NPF; for example, very high frequency (86$100 \%)$ and high magnitude $\left(\sim 700-3960 \mathrm{~cm}^{-3} N_{4-9}\right.$ and $\sim 1000-3990 \mathrm{~cm}^{-3} N_{4-2000}$ ) of NPF were observed in the mid-latitude tropopause region due to air mixing (Young et al., 2007). On the other hand, this trend is different from the previous report by Lee et al. (2003) which showed higher concentrations of ultrafine particles in the lower latitudes. Because a majority of the data in Lee et al. (2003) were taken in the subtropics and polar regions, rather than in the midlatitutes, while the present study was made mostly in the midlaltitude region, a direct comparison between Lee et al. (2003) and this study is difficult.

\section{Discussions and conclusion}

Because surface area is the sink of new particles, an anticorrelation of $N_{4-9}$ with surface area might be expected. However, our analysis shows little correlation between these two parameters, although the median value of surface areas was higher for non-NPF events than NPF events. This is probably because that the majority of the samples (95\%) were NPF cases and the measurements were made in a wide range of the free troposphere region (altitudes up to $14 \mathrm{~km}$ and latitudes from $18^{\circ} \mathrm{N}-62^{\circ} \mathrm{N}$ ). This feature in fact is also consistent with Ström et al. (1999) which showed that ultrafine particles are not always anti-correlated to surface areas in the free troposphere. The high frequency and magnitude of NPF observed in this region (Twohy et al., 2003; Young et al., 2007; Hermann et al., 2003; Lee et al., 2003; this study) are thus due to such low surface areas measured in this region in general $\left(4-6 \mu \mathrm{m}^{2} \mathrm{~cm}^{-3}\right.$ on average (Young et al., 2007); $3.4 \pm 1.7 \mu \mathrm{m}^{2} \mathrm{~cm}^{-3}$ (Lee et al., 2003); $<10 \mu \mathrm{m}^{2} \mathrm{~cm}^{-3}$ (Twohy et al., 2003; Carslaw and Kärcher, 2006); $1.58 \pm 0.87 \mu \mathrm{m}^{2} \mathrm{~cm}^{-3}$ from the present study) and in addition to low temperatures (Carslaw and Kärcher, 2006).

Our case studies shown in this study indicate that airmass history is important for nucleation in this region. All non/weak-NPF cases identified here did not have large scale vertical motion, indicating that airmasses originated from relatively high altitudes, possibly with low concentrations of expected aerosol precursors. On the other hand, strong events usually had uplifting. Large scale uplifting brings higher concentrations of aerosol precursors (including $\mathrm{SO}_{2}$ and water vapor) to higher altitudes where temperature and surface areas are lower. With these factors together, uplifting can create an ideal condition for aerosol NPF: higher aerosol precursors, lower surface areas, low temperatures, and air mixing. It is noted that the $\mathrm{SO}_{2}$ photochemical lifetime in 
the atmosphere is around 10-14 days under the typical free tropospheric conditions. Even with this relatively long photochemical lifetime, however, the measured $\mathrm{SO}_{2}$ concentrations in the free troposphere showed a clear vertical profile, with much lower concentrations at higher altitudes than in the ground level (Thornton et al., 1999). In this case, uplifting can play a very important role for bringing higher concentrations of $\mathrm{SO}_{2}$ from the source regions to higher altitudes in a short time. In addition, it is possible that rapid uplifting can also bring insoluble organic trace gases to higher altitudes to produce new particles (Kulmala et al., 2006). Abrupt air mixing can also take place during rapid uplifting. As shown in previous theoretical predictions (Nilsson and Kulmala., 1998), because nucleation is a non-linear process, when two airmasses mix with each other with different RHI, temperatures, and aerosol precursors, nucleation rates can be much higher than without mixing.

While the role of uplifting of an airmass on NPF is much clear, it is less clear how other meteorological parameters from the airmass history can also play a role in determining if nucleation occurs and the extent to which it occurs (Table 2). The solar flux from the previous five days was similar for the strong- and weak- NPF events for both case studies and if the sun exposure fraction (that is the average ratio of the sun exposure hours in a day during the five preceding days) also did not vary much day to day (approximately 0.5 to 0.6 ), so the average $\mathrm{OH}$ concentrations in airmasses would be similar. While the RHI was higher for the strong event than the weak event on 12 December, the values were comparable for both events on December 19 (Table 2). Precipitation may have affected the strength of the event as in both cases the strong event experienced more cumulative precipitation (Table 2). Precipitation is believed to lower the surface area density because of scavenging, but since for all these events the surface areas were in fact very low in this region, the precipitation effects can be less important under such a condition. For these specific case studies, however, the altitude rather seems to be a dominating factor in determining the strength of the NPF event. Both strong events had a median altitude of less than $2.5 \mathrm{~km}$ during the previous five days and had minimum altitudes very close to the ground level $(<1 \mathrm{~km})$, whereas for the weak events the median altitudes were both above $6 \mathrm{~km}$ and the air never fell below $2 \mathrm{~km}$ (Table 2). And, this may again point to the significance of airmass history in determining the extent of NPF.

It was consistent that weak- or non-events did not experience large scale uplifting during the Progressive Science Missions. Because of low surface areas and low temperatures, nucleation can easily take place, but with the limited supply of aerosol precursors in this region, nucleation becomes sensitive to the extent of vertical motion. Our observations are inline with numerous observations (de Reus et al., 1998; Nyeki et al., 1999; Ström et al., 1999; Twohy et al., 2002; Lee et al., 2003; Minikin et al., 2003; Hermann et al., 2003; Carslaw and Kärcher, 2006) in which NPF was of-
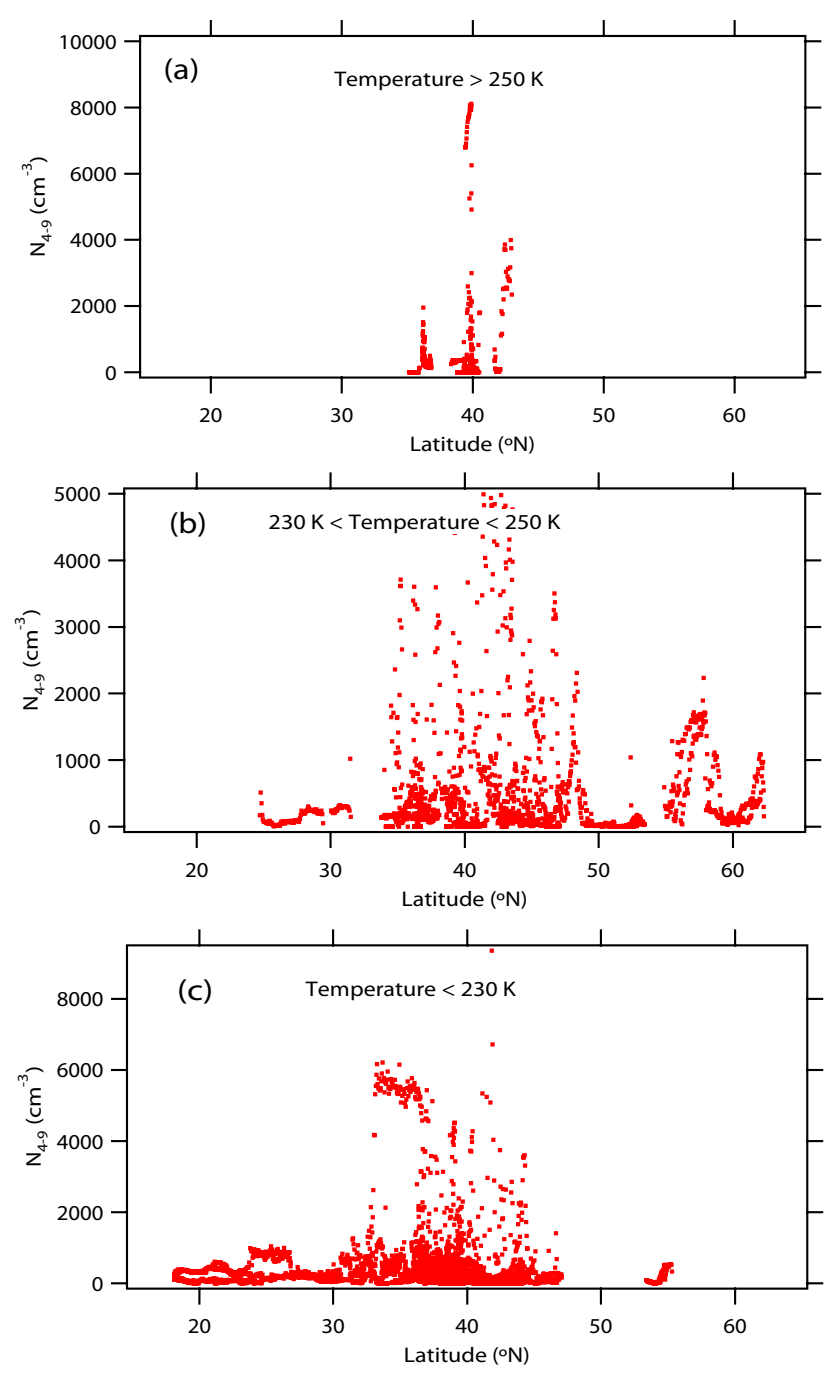

Fig. 8. The measured $N_{4-9}$ as a function of latitude for different temperatures (and hence different altitudes) during the NSF/NCAR GV Progressive Science Mission. All 7 research flights are included here. Temperatures $>250 \mathrm{~K}$ (Altitudes $<6 \mathrm{~km}$ ); $230 \mathrm{~K}<$ Temperatures $<250 \mathrm{~K}(6 \mathrm{~km}<$ Altitudes $<9 \mathrm{~km})$; Temperatures $<230 \mathrm{~K}$ (Altitudes $>9 \mathrm{~km}$ ).

ten attributed to air mixing and convection. However, there were also some NPF cases where vertical motion clearly did not occur $(<50 \%$ of the NPF cases), similarly to Young et al. (2007), suggesting that airmass history is an important but not the only governing factor for aerosol nucleation in this region.

Acknowledgements. This study was supported by NSF grants awarded to KSU (ATM-0507709; CAREER ATM-0645567). NCAR is supported by NSF, but any opinions expressed here do not represent those from NSF. We thank James C. Wilson for providing NMASS and FCAS and helpful discussions, and the scientists, engineers and pilots involved in the NSF/NCAR GV Progressive Science Missions. We also thank two reviewers for helpful comments. 
Edited by: D. Cziczo

\section{References}

Brock, C. A., Schrörder, F., Kärcher, B., Petzold, A., Busen, R., and Fiebig, M.: Ultrafine particle size distributions measured in aircraft exhaust plumes, J. Geophys. Res., 105, 26555-26567, 2000.

Carslaw, K. S. and Kärcher, B.: Stratospheric aerosol processes, Chap. 1, in: Stratospheric Processes and Their Role in Global Climate (SPARC), A Project of WMO/ICSU/IOC World Climate Research Program: Assessment of Stratospheric Aerosol Properties (ASAP), edited by: Thomason, and Peter, Th., SPARC Scientific Steering Group, February 2006, http://www.atmosp. physics.utoronto.ca/SPARC/ASAP\%20V3c1.pdf, 2006.

de Reus, M., Ström, J., Kulmala, M., Pirjola, L., Lelieveld, J., Schiller, C., and Zöger, M.: Airborne aerosol measurements in the tropopause region and the dependence of NPF on preexisting number concentration, J. Geophys. Res., 103, 31 255-31 263, 1998.

de Reus, M., Ström, J., Hoor, R., Lelieveld, J., and Schiller, C.: Particle production in the lowermost stratosphere by convective lifting of the tropopause, J. Geophys. Res., 104, 23 935-23 940, 1999.

Draxler, R. R. and Rolph, G. D.: HYSPLIT (HYbrid Single-Particle Lagrangian Integrated Trajectory) Model access via NOAA ARL READY Website (http://www.arl.noaa.gov/ready/hysplit4.html), NOAA Air Resources Laboratory, Silver Spring, MD, 2003.

Hermann, M., Heintzenberg, J., Wiedensohler, A., Zahn, A., Heinrich, G., and Brenninkmeijer, C. A. M.: Meridional distributions of aerosol particle number concentrations in the upper troposphere and lower stratosphere obtained by Civil Aircraft for Regular Investigation of the Atmosphere Based on an Instrument Container (CARIBIC) flights, J. Geophys. Res., 108, 4114, doi:10.1029/2001JD001077, 2003.

Jonsson, H. H., Wilson, J. C., Brock, C. A., Knollenberg, R. G., Newton, R., Dye, J. E., Baumgardner, D., Borrmann, S., Ferry, G. V., Pueschel, R., Woods, D. C., and Pitts, M. C.: Performance of a focused cavity aerosol spectrometer for measurements in the stratosphere of particle size in the $0.06-2.0 \mu \mathrm{m}$ diameter range, J. Atmos. Ocean Technol., 12, 115-129, 1995.

Kulmala, M., Reissell, A., Sipilä, M., Bonn, B., Ruuskanen, T. M., Lehtinen, K. E. J., Kerminen, V.-M., and Ström, J.: Deep convective clouds as aerosol production engines: Role of insoluble organics, J. Geophys. Res., 111, D17202, doi:10.1029/2005JD006963, 2006.

Lee, S. H., Reeves, J. M., Wilson, J. C., Hunton, D. E., Viggiano, A. A., Miller, T. M., Ballenthin, J. O., and Lait, L. R.: Particle formation by ion nucleation in the upper troposphere and lower stratosphere, Science, 301, 1886-1889, 2003.

Lee, S.-H., Wilson, J. C., Baumgardner, D., Herman, R. L., Weinstock, E. M., LaFleur, B. G., Kok, G., Anderson, B., Lawson, P., Baker, B., Strawa, A., Pittman, J. V., Reeves, J. M., and Bui, T. P.: NPF observed in the tropical/subtropical cirrus clouds, J. Geophys. Res., 109, D02009, doi:10.1029/2004JD005033, 2004.
Lee, S.-H., Young, L.-H., Benson, D. R., Suni, T., Kulmala, M., Junninen, H., Campos, T. L., Rogers, D. C., and Jensen, J.: Observations of Nighttime NPF in the Troposphere, J. Geophys. Res., 113, D10210, doi:10.1029/2007JD009351, 2008.

Mertes, S., Galgon, D., Schwirn, K., Nowak, A., Lehmann, K., Massling, A., Wiedensohler, A., and Wieprecht, W.: Evolution of particle concentration and size distribution observed upwind, inside and downwind hill cap clouds at connected flow conditions during FEBUKO, Atmos. Environ., 39, 4233-4245, 2005.

Minikin, A., Petzold, A., Ström, J., Krejci, R., Seifert, M., Velthoven, P. V., Schlager, H., and Schumann, U.: Aircraft observations of the upper tropospheric fine particle aerosol in the northern and southern hemispheres at midlatitudes, Geophys. Res. Lett., 30, 1503, doi:10.1029/2002GL016458, 2003.

Nilsson, E. D. and Kulmala, M.: The potential for atmospheric mixing processes to enhance binary nucleation rate, J. Geophys. Res., 103, 1381-1389, 1998.

Nyeki, S., Kalberer, M., Lugauer, M., Weingartner, E., Petzold, A., Schröder, F., Colbeck, I., and Baltensperger, U.: Condensation Nuclei $(\mathrm{CN})$ and ultrafine $\mathrm{CN}$ in the free troposphere to $12 \mathrm{~km}$ : A case study over the Jungfraujoch high-alpine research station, Geophys. Res. Lett., 26, 2195-2198, 1999.

Pan, L. L., Bowman, K. P., Shapiro, M., Randel, W. J., Gao, R., Campos, T., Davis, C., Schauffler, S., Ridley, B. A., Wei, J. C., and Barnet, C.: Chemical behavior of the tropopause region observed during the Stratosphere-Troposphere Analyses of Regional Transport (START) experiment, J. Geophys. Res., 112, D18110, doi:10.1029/2007JD008645, 2007.

Ström, J., Fischer, H., Lelieveld, J., and Schröder, F.: In situ measurements of microphysical properties and trace gases in two cumulonimbus anvils over western Europe, J. Geophys. Res., 104, 12 221-12 226, 1999.

Thornton, D. C., Bandy, A. R., Blomquist, B. W., Driedger, A. R., and Wade, T. P.: Sulfur dioxide distribution over the Pacific Ocean 1991-1996, J. Geophys. Res., 104, 5845-5854, 1999.

Twohy, C. H., Clement, C. F., Gandrud, B. W., Weinheimer, A. J., Campos, T. L., Baumgardner, D., Brune, W. H., Faloona, I., Sachse, G. W., Vay, S. A., and Tan, D.: Deep convection as a source of new particles in the midlatitude upper troposphere, J. Geophys. Res., 107, 4560, doi:10.1029/2001JD000323, 2002.

Wiedensohler, A., Hansson, H.-C., Orsini, D., Wendisch, M., Wagner, F., Bower, K. N., Choularton, T. W., Wells, M., Parkin, M., Acker, A., Wieprecht, W., Fachini, M. C., Lind, J. A., Fuzzi, S., Arends, B. G., and Kulmala, M.: Nighttime formation and occurrence of new particles associated with orographic clouds, Atmos. Environ., 31, 2545-2559, 1997.

Young, L.-H., Benson, D. R., Montanaro, W. M., Lee, S.-H., Pan, L. L., Rogers, D. C., Jensen, J., Stith, J. L., Davis, C. A., Campos, T. L., Bowman, K. P., Cooper, W. A., and Lait, L. R.: Enhanced NPF observed in the northern midlatitude tropopause region, J. Geophys. Res., 112, D10218, doi:10.1029/2006JD00810, 2007. 